\title{
Die Geburtshaus-Tassen der DRG
}

Auf dem diesjährigen Deutschen Röntgenkongress in Leipzig hatten Sie erstmals Gelegenheit, unsere vom Künstler Hubert Heinrich (www.hubertheinrich.de) gestalteten Geburtshaus-Tassen zu erwerben.

Die in limitierter Auflage qualitativ hochwertig angefertigten und bedruckten Tassen möchten wir Ihnen nun zu besonderen Set-Preisen anbieten. Wählen Sie aus zwei Motiven oder einer Kombination aus beiden und bringen Sie Farbe in Ihren Berufsalltag:

Variante I

- $10 \times$ Motiv Haus oder Röntgen $=200,00$ Euro

- 20× Motiv Haus oder Röntgen $=350,00$ Euro

- $30 \times$ Motiv Haus oder Röntgen $=500,00$ Euro

Variante II

$\checkmark 5 \times$ Haus und $5 \times$ Röntgen $=200,00$ Euro

- $10 \times$ Haus und $10 \times$ Röntgen $=350,00$ Euro

- $15 \times$ Haus und $15 \times$ Röntgen $=500,00$ Euro

Für die von Ihnen erworbenen Tassen erhalten Sie eine Rechnung. Alle Einnahmen fließen direkt in die Renovierung und den Ausbau des Wilhelm-Conrad-Röntgen-
Geburtshauses. Der Versand erfolgt über DHL.

Das Bestellformular finden Sie auf www. roentgen-geburtshaus.de > Aktuelles > Die Geburtshaus-Tassen der DRG.

Das ausgefüllte Bestellformular senden Sie bitte per Mail an ermisch@drg.de oder per Fax an 030-916 070-22, z.H. Sandra Ermisch

Vielen Dank für Ihre Unterstützung!

Ihre Geburtshaus-Wilhelm-ConradRöntgen-Stiftung

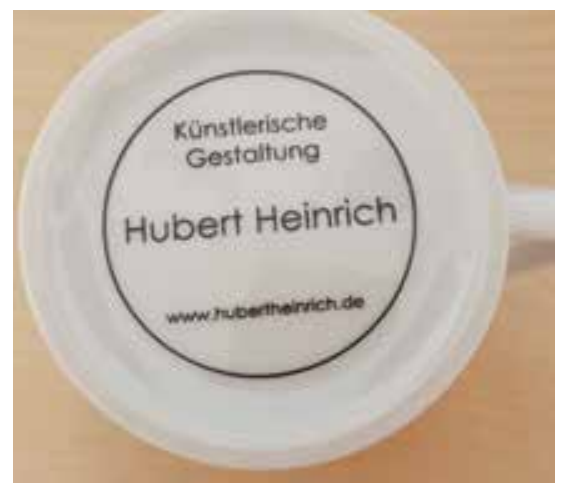

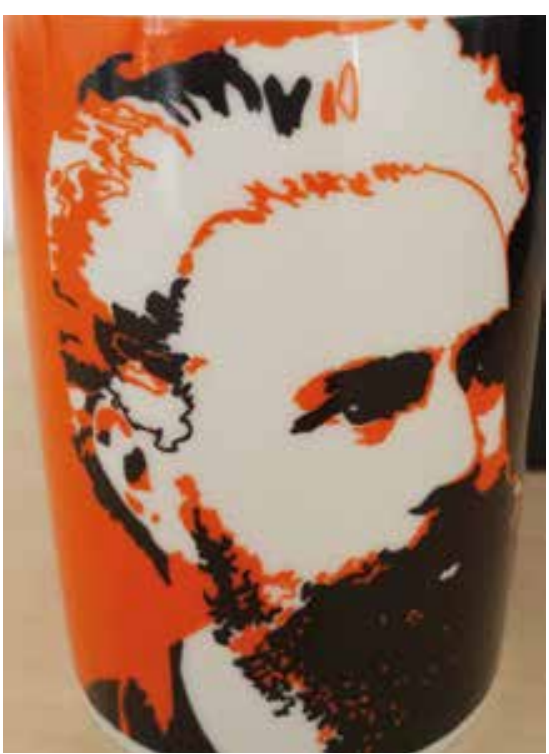

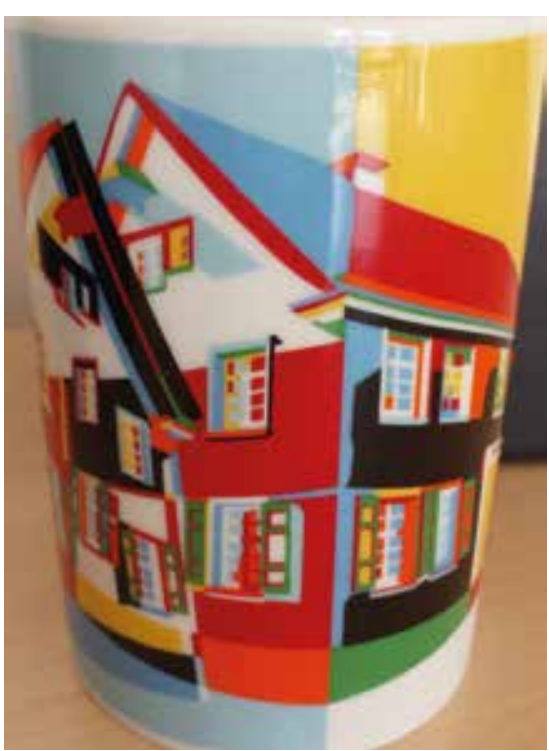

